Research Article

\title{
Life Skills Intervention for Behavioural Change among Students of a Government High School in Karnataka
}

\author{
Srividya RN', Pradeep BS ${ }^{2}$, Swati Shahane ${ }^{3}$, Mutharaju Arelingaiah ${ }^{4}$, Lavanya Garady ${ }^{5}$, \\ Gireesh $\mathrm{H}^{6}$, Gananath Shetty Yekkaru ${ }^{7}$, Lokesh $\mathrm{M}^{8}$
}

${ }^{1}$ Research Coordinator, ${ }^{3}$ Program Coordinator, Life Skills Counselling Services Program, ${ }^{2}$ Additional Professor, Department of Epidemiology, Centre for Public Health, NIMHANS, Bengaluru, Karnataka, India.

${ }^{4}$ Program Coordinator, Yuva Spandana Program, Dept. of Epidemiology, Centre for Public Health, NIMHANS, Bengaluru, Karnataka, India. ${ }_{5}^{5}$ Senior Programme Executive, International Centre for Public Health Innovations, Ramaiah, Bengaluru, Karnataka, India.

${ }^{6}$ Monitoring and Evaluation Officer, Life Skills Program, Dept. of Epidemiology, Centre for Public Health, NIMHANS, Bengaluru, Karnataka, India.

7Joint Secretary (Ex-Officio) and State Liaison Officer, National Services Scheme Wing, Dept. of Youth Empowerment and Sports, Government of Karnataka, Karnataka, India.

${ }^{8}$ Former Deputy Commissioner/ District Collector, Shivamogga, Government of Karnataka, Karnataka, India.

DOI: https://doi.org/10.24321/2349.2880.201919

\section{I $\quad \mathbf{N} \quad \mathbf{F} \quad \mathbf{O}$}

\section{Corresponding Author:}

Pradeep BS, Department of Epidemiology, Centre for Public Health, NIMHANS, Bengaluru, Karnataka, India.

\section{E-mail Id:}

doctorpradeepbs@gmail.com

Orcid Id:

https://orcid.org/0000-0002-0894-460X

How to cite this article:

Srividya RN, Pradeep BS, Shahane S, Arelingaiah M, Lavanya G, Gireesh HJ et al. Life Skills Intervention for Behavioural Change among Students of a Government High School in Karnataka. Ind J Youth Adol Health 2019; 6(4): 26-32.

Date of Submission: 2020-04-01 Date of Acceptance: 2020-05-01

\section{$\begin{array}{lllllllllll}\mathbf{A} & \mathbf{B} & \mathbf{S} & \mathbf{T} & \mathbf{R} & \mathbf{A} & \mathbf{C} & \mathbf{T}\end{array}$}

\begin{abstract}
Adolescence is a transitional phase with physical, social and psychological changes. With the influence of rapid societal changes, it has become difficult for teachers and parents to manage adolescents. A government school in Karnataka had approached to provide behavioural intervention session for their students. A tailor-made life skills intervention aimed at bringing behavioural changes among students was designed. Our objective was to assess the effectiveness of a four-day life skills intervention on change in behaviour among students of a government high school in Karnataka. A semistructured Pre- and post-test self-administered questionnaire which included a Strengths and Difficulties Questionnaire was administered to participants. This tailor-made intervention for adolescents in a school showed significant improvement in emotional symptoms $(p=0.002)$ following the intervention. The intervention was provided to 137 students. It was observed that out of 17 (21\%) participants who reported to have borderline symptoms for strengths and difficulties, 13 (76\%) participants improved after training. Out of 7 (8.7\%) participants who reported to have abnormal symptoms for strengths and difficulties during pre-test, about 5 (71\%) participants improved post-training. There was improvement in all other domains of strengths and difficulties namely conduct problem, hyperactivity, peer relationship and prosocial behaviour scales, although not statistically significant. The total strengths and difficulties score decreased overall. Individually strengths and difficulties showed movement more towards the normal end rather than the abnormal end of the spectrum of strengths and difficulties scores. The result of this tailor-made intervention program has implications for adolescents from similar socio-economic background as well as adaptation of this intervention among adolescents in different situations.
\end{abstract}

Keywords: Adolescents, Life Skills Intervention, Strengths 


\section{Introduction}

Adolescence (10 to 19 years) is a phase of rapid growth and development during which physical, psychological and behavioural changes occur. ${ }^{1}$ There are more than 1.2 billion adolescents worldwide. They stand at the crossroads between childhood and the adulthood. About $21 \%$ of Indian population and $18 \%$ of Karnataka state's population are adolescents. ${ }^{2}$ It is a period of preparation for undertaking familial, social, cultural and economic responsibilities in adulthood.

Health status of an adolescent determines the health status in his/ her adulthood. The health needs of an adolescent can be categorised into three: physical, psychological and social. Mental health issues, infectious diseases, violence, unintentional injuries, malnutrition and substance use are major health issues faced by adolescents. ${ }^{3}$ Psychological and social problems include issues related to behaviour and also that they face in school. These are more common during adolescence than at any other time of childhood.

Professional intervention needs to evaluate individuals when misbehaviour becomes severe and frequent particularly depression, anxiety, gang membership, violence, substance use, hyperactive behaviour etc. Significant signs include regular use of substance, attack/ assault in peer group, absenteeism, theft, under performance at school, running away from home, serious injuries or use of weapons. ${ }^{4}$

To create a positive environment to decrease mental health problems in youth, the Department of Youth Empowerment and Sports (DYES) in collaboration with Department of Epidemiology, Centre for Public Health (CPH) NIMHANS has launched an adolescent and youth focused mental health promotion program titled 'Yuva Spandana' and a complimentary program called 'Life Skills training and counselling services program' to bring positive changes in lives of youth in Karnataka.

Yuva Spandana is a program for bridging the gap between youth, their families and ever changing society in order to enable smooth transition of youth from childhood to adulthood by providing behavioural, mental and psychological support services. Life skills training is an efficacious tool for empowering the youth to act responsibly, take initiative and take control. ${ }^{5}$

It is known that life skills training imparts knowledge and develops attitudes and skills that support adoption of healthy behaviours. ${ }^{6}$ The training program on life skills provide a range of ten skills for life, brings about the desired transformation in them and in the society. Although adolescence is generally considered healthy period in life, several important health and social behaviour problems either start or peak during these years (e.g., substance use).
Both these programs Yuva Spandana and Life skills training act as tools of group intervention for children and adults (parents and teachers of the school) in addressing adolescent psychological and social problems such as impulsivity, hyperactivity, anxiety, boredom, vandalism, bullying, running away, theft etc. The training builds upon the social learning theory and on what we know of how youth learn from their environment, from observing how others behave and what consequences arise from behaviour.

As part of the Yuva Spandana and life skills intervention a specific intervention for adolescents was planned to be implemented among class 10 students of a school reported to have difficulties in coping up with society and within the family. This paper reports the effect of a tailor-made life skills intervention on strengths and difficulties of the participants.

\section{Materials and Methods}

The study was conducted at Public High School, in a district at Karnataka from $13^{\text {th }}$ September 2017 to $16^{\text {th }}$ September 2017. All 137 students of class 10 who participated in Life Skills and Yuva Spandana sensitisation program consented to participate and were included in the study.

Teachers of the school were contacted to identify the intervention needs to facilitate development of an appropriate tailor-made intervention package. This intervention helped us to understand the social circumstance of students as well. The students were hailing from low income communities and majority of them had to support their family along with their schooling. There were behaviour issues, absenteeism, lack of interest in studies, aggressiveness, unhealthy peer relationships, hyperactivity, etc. Considering the identified needs and age of the participants, the intervention needed to focus on the skills which helps in changing the behaviour of students and mobilize them to seek support when needed through Yuva Spandana.

It was decided to have six out of ten life skill domains ${ }^{7}$ namely, self-awareness, empathy, effective communication, interpersonal relationships, coping with stress and coping with emotions. The entire training program was decided to be conducted through experiential learning. This approach involves 4 components namely Activity (an activity is given to participants to have an experience of the skill), Reflective observation (participant's opinion on the experience of the activity and learning is known by the facilitator), Abstract conceptualization (concept is delivered to the participants uniting their responses and experience of the activity), and Delivery tips (application of the experience and take home message is given to the participants on a given concept).

The 4-day module consisted of 2 days intervention for the 
students, one day of support/guidance was provided and on the last day parent-teacher intervention was held.

\section{Study Instrument and Data Collection}

All subjects who participated were given a pre-test questionnaire before the intervention. A post-test questionnaire was provided immediately post intervention. A semi structured self-administered pen and paper questionnaire was used to collect data for the study. The project staff trained in questionnaire administration facilitated data collection in case the respondent had any clarifications. The questionnaire was in Kannada (local language). Pre-test questionnaire had 7 sections, and post-test questionnaire had 5 sections as there would be no changes in sections such as family information, peer group and social capital within the duration of training. The sections were sociodemographic information, family information, peer group and social capital, strengths and difficulties questionnaire, screening questions related to substance use, injuries, self-harm behaviour, usage of mobile phones and media related information.

The strengths and difficulties questionnaire is a 25-item questionnaire developed by Robert $\mathrm{N} \mathrm{Goodman}{ }^{8}$ consisting of 5 domains namely emotional symptoms, conduct problem scale, prosocial behaviour, hyperactivity and peer problem scale. This is a validated instrument used in multiple settings with a Cronbach's alpha for the subscales ranging from 0.44 to 0.71 . Considering the similarity in age and need of the participants Strengths and Difficulties Questionnaire (SDQ) was utilized.

\section{Statistical Analysis}

We performed descriptive analysis along with Wilcoxon signed rank test to compare strengths and difficulties score before and after training.

\section{Result}

Table I.Sociodemographic characteristics of participants

\begin{tabular}{|c|c|c|c|}
\hline Sections & & Number & $\%$ \\
\hline \multirow{2}{*}{ Gender } & Boys & 99 & 72.3 \\
\cline { 2 - 4 } & Girls & 38 & 27.7 \\
\hline \multirow{2}{*}{ Religion } & Hindu & 104 & 75.9 \\
\cline { 2 - 4 } & Others & 33 & 24.1 \\
\hline Age & Mean \pm SD & $14.81 \pm 0.88$ \\
\hline $\begin{array}{c}\text { Number of family } \\
\text { members }\end{array}$ & Median (IQR) & \multicolumn{2}{|c|}{$5(1)$} \\
\hline
\end{tabular}

There were 137 participants, with majority (72.3\%) being boys with a mean age of $14.81 \pm 0.88$ years (Table 1 ).
Table 2.Peer characteristics of participants

\begin{tabular}{|c|c|c|c|}
\hline Section & & No. & $\%$ \\
\hline \multirow{5}{*}{$\begin{array}{l}\text { Habits of } \\
\text { participants }\end{array}$} & Smoking & 3 & 2.2 \\
\hline & $\begin{array}{c}\text { Smokeless Tobacco } \\
\text { Products }\end{array}$ & 2 & 1.5 \\
\hline & Alcohol Consumption & 3 & 2.2 \\
\hline & Usage of drugs & 2 & 1.5 \\
\hline & Sniffing & 3 & 2.2 \\
\hline $\begin{array}{l}\text { Number of } \\
\text { friends }\end{array}$ & Median (IQR) & \multicolumn{2}{|c|}{$10(16)$} \\
\hline \multirow{5}{*}{$\begin{array}{l}\text { Activities with } \\
\text { friends }\end{array}$} & Study & 100 & 73 \\
\hline & Passing time & 108 & 78.8 \\
\hline & Going to a movie & 47 & 34.3 \\
\hline & Eating out & 74 & 54 \\
\hline & Others & 18 & 13.1 \\
\hline \multirow{4}{*}{$\begin{array}{l}\text { Number of } \\
\text { friends who } \\
\text { could help } \\
\text { Financially }\end{array}$} & Nobody & 28 & 20.4 \\
\hline & 1 or 2 & 81 & 59.1 \\
\hline & 3 or 4 & 14 & 10.2 \\
\hline & $>=5$ & 14 & 10.2 \\
\hline \multirow{3}{*}{$\begin{array}{l}\text { Number of } \\
\text { friends who } \\
\text { could } \\
\text { provide shelter }\end{array}$} & Yes & 88 & 64.2 \\
\hline & No & 31 & 22.6 \\
\hline & Don't know & 18 & 13.1 \\
\hline \multirow{4}{*}{ Habits of friends } & Smoking & 04 & 2.9 \\
\hline & $\begin{array}{c}\text { Smokeless } \\
\text { Tobacco products }\end{array}$ & 02 & 1.5 \\
\hline & Alcohol consumption & 02 & 1.5 \\
\hline & Usage of drugs & 01 & 0.7 \\
\hline \multirow{4}{*}{$\begin{array}{l}\text { Other activities } \\
\text { with friends }\end{array}$} & Crime & 09 & 6.6 \\
\hline & Gang activities & 25 & 18.2 \\
\hline & Commenting & 21 & 15.3 \\
\hline & Strikes & 17 & 12.4 \\
\hline \multirow{2}{*}{$\begin{array}{l}\text { Ever been to jail } \\
\text { (Friends) }\end{array}$} & Yes & 06 & 4.4 \\
\hline & No & 131 & 95.6 \\
\hline $\begin{array}{l}\text { Ever been to jail } \\
\text { (Self) }\end{array}$ & No & 137 & 100 \\
\hline \multirow{2}{*}{$\begin{array}{c}\text { Part of any } \\
\text { group/ } \\
\text { Organization }\end{array}$} & Yes & 27 & 19.7 \\
\hline & No & 110 & 80.3 \\
\hline \multirow{2}{*}{$\begin{array}{l}\text { Usage of mobile } \\
\text { phone }\end{array}$} & Yes & 12 & 8.8 \\
\hline & No & 125 & 91.2 \\
\hline
\end{tabular}

*Percentage total do not add up to hundred since multiple responses were possible. 
The participants had a median of 10 friends, overall. Majority of them opined that they study (73\%), simply pass time (78\%) and go out to eat (54\%) with friends. About one-third of them even go to movies with friends (34.3\%). About $20.4 \%$ (28) of the participants do not seek any financial help from their friends/peer and about $10.2 \%$ (14) of the participants seek financial help from more than their 5 friends/peers. About 2.2\% (3) of participants have the habit of smoking, consuming alcohol and sniffing drugs. Approximately 3\% (4) of their friends have the habit of smoking and only $0.7 \%$ (1) of their peers use drugs. About one fifth (19.7\%) of them are part of a group/organization and majority (91.2\%) of them do not use mobile phones (Table 2).

A decrease in total scores of strengths and difficulties after training was observed. This was not statistically significant $(p<0.256)$. Among all the sub-scales, significant difference was observed in Emotional Symptoms Scale $(p<0.002)$ immediately post training. Scores of all other domains of strengths and difficulties showed a decrease but was not statistically significant (Table 3).

About $30 \%$ of the participants had either borderline (21.25\%) or abnormal (8.75\%) strengths and difficulties before training. Among them 13 participants in the borderline group (76\%) improved and showed normal strengths and difficulties, while one of them deteriorated and showed abnormal strengths and difficulties. Majority ( 85\%) of those who had abnormal strengths and difficulties improved to borderline (14.28\%) and normal (71.42\%) strengths and difficulties post training. About a quarter of participants who were normal pre-training deteriorated to borderline (16.07\%) and abnormal (7.14\%) strengths and difficulties after training (Table 4).

Table 3.Comparison of strength and difficulties score before and after training

\begin{tabular}{|c|c|c|c|c|}
\hline Strength and difficulty & $\mathbf{N}$ & Mean \pm SD & Median (IQR) & p-value \\
\hline $\begin{array}{c}\text { Emotional Symptoms Scale } \\
\text { (Pre-test) }\end{array}$ & 109 & $4.21 \pm 2.19$ & $4(2)$ & \multirow[t]{2}{*}{$0.002 *$} \\
\hline $\begin{array}{l}\text { Emotional Symptoms Scale } \\
\text { (Post-test) }\end{array}$ & 109 & $3.52 \pm 1.88$ & $3(2)$ & \\
\hline Conduct Problem Scale (Pre-test) & 111 & $3.08 \pm 2.16$ & $2(3)$ & \multirow[b]{2}{*}{0.108} \\
\hline Conduct Problem Scale (Post-test) & 111 & $2.73 \pm 1.77$ & $3(3)$ & \\
\hline Hyperactivity Scale (Pre-test) & 108 & $3.09 \pm 1.73$ & $3(2)$ & \multirow[b]{2}{*}{0.567} \\
\hline Hyperactivity Scale (Post-test) & 108 & $2.94 \pm 1.74$ & $3(2)$ & \\
\hline Peer Problem Scale (Pre-test) & 111 & $3.10 \pm 1.46$ & $3(2)$ & \multirow[b]{2}{*}{0.701} \\
\hline Peer Problem Scale (Post-test) & 111 & $3.06 \pm 1.85$ & $3(2)$ & \\
\hline Prosocial Scale (Pre-test) & 115 & $8.65 \pm 1.57$ & $9(2)$ & \multirow[b]{2}{*}{0.547} \\
\hline Prosocial Scale (Post-test) & 115 & $8.64 \pm 1.60$ & $9(2)$ & \\
\hline Total (Pre-test) & 80 & $12.70 \pm 4.79$ & $13(7)$ & \multirow[b]{2}{*}{0.256} \\
\hline Total (Post-test) & 80 & $12.19 \pm 4.94$ & $11(7)$ & \\
\hline
\end{tabular}

*p-value for Wilcoxon signed rank test.

Table 4.Pre and Post intervention strengths and difficulties score among participants

\begin{tabular}{|c|c|c|c|c|c|}
\hline \multicolumn{6}{|c|}{ Total Strengths and Difficulties Score } \\
\hline & & & Post-Test & & \\
\hline \multirow{5}{*}{ Pre-Test } & & Normal & Borderline & Abnormal & Total \\
\hline & Normal & $43(76.78)^{* *}$ & $9(16.07)^{* * *}$ & $4(7.142)^{* * *}$ & $56(70)$ \\
\hline & Borderline & $13(76.47)^{*}$ & $3(17.64)^{* *}$ & $1(5.882)^{* * *}$ & $17(21.25)$ \\
\hline & Abnormal & $5(71.42)^{*}$ & $1(14.28)^{*}$ & $1(14.28)^{* *}$ & $7(8.75)$ \\
\hline & Total & $61(76.25)$ & $13(16.25)$ & $6(7.5)$ & $80(100)$ \\
\hline
\end{tabular}

*Participants who have shown improvement after training.

**Participants who have remained in the same category.

***Participants who have shown deterioration after training. 
Table 5.Changes in scores of all 5 domains of strengths and difficulties across participants

\begin{tabular}{|c|c|c|c|c|}
\hline \multirow{2}{*}{$\begin{array}{c}\text { Pre-test } \\
\text { Emotional Symptoms Scale ( } \mathrm{N}=109 \text { ) }\end{array}$} & \multicolumn{4}{|c|}{ Post-test } \\
\hline & Normal & Borderline & Abnormal & Total \\
\hline Normal & $67(82.71)^{* *}$ & $9(11.11)^{* * *}$ & $5(6.172)^{* * *}$ & $81(74.31)$ \\
\hline Borderline & $12(85.71)^{*}$ & $2(14.28)^{* *}$ & $0(0)^{* * *}$ & $14(12.84)$ \\
\hline Abnormal & $11(78.57)^{*}$ & $0(0)^{*}$ & $3(21.42)^{* *}$ & $14(12.84)$ \\
\hline Total & $90(82.56)$ & $11(10.09)$ & $8(7.339)$ & $109(100)$ \\
\hline \multicolumn{5}{|l|}{ Conduct Problem Scale ( $\mathrm{N}=111$ ) } \\
\hline Normal & $53(76.81)^{* *}$ & $10(14.49)^{* * *}$ & $6(8.695)^{* * *}$ & $69(62.16)$ \\
\hline Borderline & $9(64.28)^{*}$ & $2(14.28)^{* *}$ & $3(21.42)^{* * *}$ & $14(12.61)$ \\
\hline Abnormal & $14(50)^{*}$ & $2(7.142)^{*}$ & $12(42.85)^{* *}$ & $28(25.22)$ \\
\hline Total & $76(68.46)$ & $14(12.61)$ & $21(18.91)$ & $111(100)$ \\
\hline \multicolumn{5}{|l|}{ Hyperactivity Scale ( $N=108)$} \\
\hline Normal & $8(50)^{* *}$ & $4(25)^{* * *}$ & $4(25)^{* * *}$ & $16(14.81)$ \\
\hline Borderline & $90(100)^{*}$ & $0(0)^{* *}$ & $0(0)^{* * *}$ & $90(83.33)$ \\
\hline Abnormal & $2(100)^{*}$ & $0(0)^{*}$ & $0(0)^{* *}$ & $2(1.851)$ \\
\hline Total & $100(92.59)$ & $4(3.703)$ & $4(3.703)$ & $108(100)$ \\
\hline \multicolumn{5}{|l|}{ Peer Problem Scale ( $\mathrm{N}=111)$} \\
\hline Normal & $46(68.65)^{* *}$ & $15(22.38)^{* * *}$ & $6(8.955)^{* * *}$ & $67(60.36)$ \\
\hline Borderline & $18(46.15)^{*}$ & $18(46.15)^{* *}$ & $3(7.692)^{* * *}$ & $39(35.13)$ \\
\hline Abnormal & $1(20)^{*}$ & $4(80)^{*}$ & $0(0)^{* *}$ & $5(4.504)$ \\
\hline Total & $65(58.55)$ & $37(33.33)$ & $9(8.108)$ & $111(100)$ \\
\hline \multicolumn{5}{|l|}{ Prosocial Scale ( $\mathrm{N}=118$ ) } \\
\hline Normal & $108(98.18)$ & $2(1.818)^{* * *}$ & $0(0)^{* * *}$ & $110(93.22)$ \\
\hline Borderline & $1(50)^{*}$ & $0(0)^{* *}$ & $1(50)^{* * *}$ & $2(1.694)$ \\
\hline Abnormal & $3(50)^{*}$ & $3(50)^{*}$ & $0(0)^{* *}$ & $6(5.084)$ \\
\hline Total & $112(94.9)$ & $5(4.237)$ & $1(0.847)$ & $118(100)$ \\
\hline
\end{tabular}

*Participants who have shown improvement after training.

**Participants who have remained in the same category.

***Participants who have shown deterioration after training

About 28 (25.6\%) participants had either borderline or abnormal emotional symptoms before training, 23 (82\%) among them improved and showed normal emotional symptoms after training. Among 81 (74.31\%) participants who showed normal emotional symptoms before training $14(17.3 \%)$ of them deteriorated and showed borderline or abnormal emotional symptoms post training. About 42 (37.83\%) participants had either borderline or abnormal conduct problems before training, 25 (59.5\%) among them improved post-training. About $92(85.18 \%)$ participants had either borderline or abnormal hyperactivity before training, all of them improved after training. About half of those who were not hyperactive (normal) pre-training, deteriorated and showed borderline or abnormal hyperactivity posttraining. About 44 (39.63\%) participants had borderline or abnormal peer problems before training. Among them $23(52.2 \%)$ participants improved and were found to be normal. Among 67 (60.36\%) participants of those who were normal with respect to peer problem scale before training, 24 (35.8\%) of them deteriorated and showed either borderline or abnormal peer problems. About 8 (6.77\%) who had either borderline or abnormal score in prosocial scale before training, 7 (87.5\%) of them improved and showed normal and borderline prosocial scores. Among 112 (94.86\%) who had normal scores before training 3 (2.67\%) of them deteriorated to borderline and abnormal prosocial score (Table 5).

\section{Discussion}

This tailor-made intervention for adolescents in a school 
showed significant improvement in emotional symptoms following the intervention. There was improvement in all other domains of strengths and difficulties namely conduct problem scale, hyperactivity, peer relationship and prosocial behaviour scales, although not statistically significant. The total strengths and difficulties score decreased overall. However, individually strengths and difficulties showed movement more towards the normal end rather than the abnormal end of the spectrum of strengths and difficulties scores.

These results of our study might hint towards the fact that such interventions might significantly affect the emotional symptoms first and then the other domains of strengths and difficulties over time. This change is also known to be affected by surrounding environment like stimulus within the family, school environment and society with which adolescents interact. ${ }^{9,10}$ This intervention is mainly focused on attitudinal change. The approach employed is facilitation and experiential learning. It is known that through this approach, the learning is likely to be retained even after the training period. ${ }^{11}$ The intervention also included the sensitization among parents and teachers. This is likely to influence improvement in strengths and difficulties of the participants over time by providing an enabling environment at school and home. However, this requires a follow-up assessment focused on the effect of such enabling environment. Given the time constraints and expert opinion, follow-up assessments were not made in this study. However, there is evidence of repeat interventions improving strengths and difficulties as well as life skills to promote a healthy and productive life among different population groups. ${ }^{12}$

This study is unique since it is tailor-made based on the needs of the participants. This was based on stake holder consultation involving mainly teachers. It would have been better, if students and their parents were also involved in developing this intervention. This was not possible due to lack of time and feasibility of inviting parents for stakeholder discussion. Teachers being closely associated with the students, they would have a more global understanding of the different issues amongst children rather than an individualistic understanding, which the parents and students might provide. However, the importance of such individualistic perspectives cannot be ignored. The results of the study can be generalised only to these students since it was based on their needs. We utilized Wilcoxon signed rank test, which is a non-parametric test. Assessment of normality of data failed and hence Wilcoxon signed rank test was employed. The assessment of the effect of this intervention utilized strengths and difficulties questionnaire which is a standardised time tested scale to assess strengths and difficulties in both clinical and community settings. ${ }^{13}$
Adolescence is a period known to shape up education, career as well as their future mental health. This is because, the risk factors associated with mental health problems like substance use, difficulties in life, ${ }^{14}$ stress associated with performance, expectations, peer influences begin during this phase. Our intervention can be seen as a mental health promotion intervention to facilitate healthy and productive future of adolescents. Support provision for those in need should also be part of any health promotion intervention. Those participants who expressed the need for support during the intervention were handled through the program Yuva Spandana. The first contact was done within the school premises and follow-up was organized within the Yuva Spandana Kendra situated in the district. This will help in provision of both immediate and long term support.

Teachers and parents are known to be effective mental health support providers. They can be guidance providers or lay counsellors for any issue the students might have. This intervention could have been more comprehensive if the parents and teachers were included in the intervention along with the students. This helps in providing an enabling environment for students both at home and school and help them improve their strengths and difficulties.

Within the study there were individuals who showed deterioration of strengths and difficulties scores in different domains. It is likely that, during the pre-test the students might not have been introspective enough in responding to these scales appropriately. This could introduce some amount of social desirability. After undergoing the intervention, they might have been more introspective and serious in responding to the scale. This might also be the case with those subjects who improved. This kind of response from the participants is difficult to quantify. However, the improvement could be much stronger in this scenario and probably provide a significant improvement in other domains of strengths and difficulties.

The intervention was for a short duration and was based on only the inputs provided by teachers about the students rather than a hands-on experience of the student behaviour. As there was no follow-up assessment, we recommend that, in future, such group intervention programs focus on a follow-up assessment. This will assess sustainability of the change in behaviour over time and provide inputs / feedback about the intervention to make necessary modifications for such interventions. We also recommend the assessment of association between substance use, usage of mobile phones and strengths and difficulties. This helps in understanding the results of this intervention better.

The results of this tailor-made intervention program have implications for adolescents from similar socio-economic background as well as adaptation of this intervention among adolescents in different situations. 


\section{Acknowledgment}

Authors would like to express their gratitude to, The Department of Youth Empowerment and Sports, Government of Karnataka for the support and financial funding for the program. Authors would also like to thank the experts, teachers, parents and students of the school where the study was conducted for taking part in the program.

\section{Sources of Funding}

This study received no funding. However, the programs Yuva Spandana and Life Skills Counselling and testing services are funded by the Department of Youth Empowerment and Sports, Government of Karnataka and State NSS Cell of the Department of Youth Empowerment and Sports, Government of Karnataka respectively.

\section{Conflict of Interest: None}

\section{References}

1. World Health Organization. Adolescents: Health Risks and Solutions: Factsheet. Fact Sheet, 2014.

2. United Nations International Children's Emergency Fund. Progress for Children. Report Card, November 2012.

3. World Health Organization. Health for World's Adolescents, 2014.

4. Sharon, Levy. Behavioral Problems in Adolescents." MSD Manual Consumer Version, February 2019. https://www.msdmanuals.com/home/children-shealth-issues/problems-in-adolescents/behavioralproblems-in-adolescents.

5. Central Board of Secondary Education. "Life Skills Education \& CCE. http://www.cbse.nic.in/cce/life_ skills_cce.pdf.

6. World Health Organization. Information Series on School Health : Skills for Health. n.d. https://www.who.int/ school_youth_health/media/en/sch_skills4health_03. pdf.

7. World Health Organization. Life skills education in schools (WHO/MNH/PSF/93. A Rev. 1) WHO. WHO, Geneva (1993).

8. Goodman, Robert, Meltzer H, Bailey V. The Strengths and Difficulties Questionnaire: A pilot study on the validity of the self-report version. European child \& adolescent psychiatry 1998; 7(3): 125-130.

9. Vranda MN, Rao MC. Life skills education for young adolescents-Indian experience. Journal of the Indian Academy of Applied Psychology 2011; 37(9): 9-15.

10. Kolb DA. Experiential Learning: Experience as the Source of Learning and Development, 1984. ofile/ David_Kolb/publication/235701029_Experiential_ Learning_Experience_As_The_Source_Of_Learning_
And_Development/links/00b7d52aa908562f9f000000. pdf.

11. Srikala B, Kumar KVK. Empowering adolescents with life skills education in schools-School mental health program: Does it work?. Indian Journal of psychiatry 2010; 52(4): 344.

12. Nair S, Ganjiwale J, Kharod N, Varma J, Nimbalkar SM. Epidemiological survey of mental health in adolescent school children of Gujarat, India. BMJ paediatrics open 2017; 1(1).

13. Marshall J, Hamilton R, Cairns N. Application of the Strengths and Difficulties Questionnaire Added Value Score in evaluating the effectiveness of Functional Family Therapy within local authority social work services. Child and Adolescent Mental Health 2018; 23(2): 85-91.

14. Aggarwal S, Berk M. Evolution of adolescent mental health in a rapidly changing socioeconomic environment: A review of mental health studies in adolescents in India over last 10 years. Asian journal of psychiatry 2015; 13: 3-12. 